\title{
Inherited Retinal Degenerations in Portugal: Addressing the Unmet Needs
}

\author{
Distrofias Hereditárias da Retina em Portugal: Ao \\ Encontro das Necessidades Não Satisfeitas
}

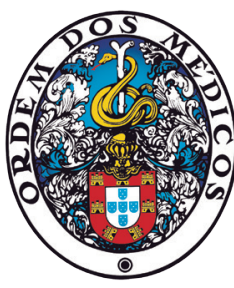

João Pedro MARQUES $\triangle^{1,2,3}$, Joana PIRES
Acta Med Port 2021 May;34(5):332-334 - https://doi.org/10.20344/amp.15802

Keywords: Genetic Therapy; Genetic Testing; Portugal; Retinal Degeneration/genetics

Palavras-chave: Degeneração Retiniana/genética; Portugal; Terapia Genética; Testes Genéticos

\section{INTRODUCTION}

Inherited retinal dystrophies/degenerations (IRDs) are a clinically and genetically heterogenous group of rare eye diseases. Despite their low prevalence ( 1:3000 individuals), ${ }^{1}$ IRDs are an important cause of severe visual impairment and blindness in children and young adults. Over the past three decades, major advances in molecular biology and human genetics have contributed to uncover the molecular basis of these disorders. Most excitingly, treatment of a particular form of congenital retinal degeneration is now possible. In December 2017, the Food and Drug Administration (FDA) approved voretigene neparvovec (Luxturna, Spark Therapeutics Inc.) to treat RPE65 mutation-associated retinal degeneration, which inevitably progresses to complete blindness by the third/fourth decade of life. Gene augmentation therapy delivers a normal copy of the native human RPE65 cDNA to the diseased retinal pigment epithelium (RPE) cells after subretinal injection of a recombinant adeno-associated virus. The transduced RPE cells then produce the RPE65 protein and the biochemical pathway leading to production of 11-cis retinal is restored, thus improving photoreceptor function. ${ }^{2}$ Results from a phase III trial demonstrated improved light sensitivity, visual fields, and navigational ability under dim lighting conditions in patients with RPE65 mutation-associated retinal degeneration. ${ }^{3}$ The clinically meaningful effect, which is nearly maximal by 30 days after the administration, is maintained at least for four years, with observations ongoing. ${ }^{4}$ In November 2018, the European Medicines Agency (EMA) granted Novartis AG marketing authorization for the use of Luxturna in Europe and several European countries have already started treatment. Not only has this newly approved therapy changed the lives of people previously destined to live a life of blindness, but it has fueled interest in developing additional gene therapy reagents targeting numerous other genetic forms of inherited retinal disease. ${ }^{2}$ The lack of a consistent RPE65 mutation-to-phenotype correlation underscores the need for widespread genetic screening in order to identify IRD patients who might benefit from this or other potential future gene therapies.

Despite some common ground, IRD genetic profiles have been shown to vary considerably among regions and ethnic groups, ${ }^{1,5}$ thus highlighting the importance of obtaining reference population-based data. A recent survey from the European Vision Institute for Clinical Research Network (EVICR.net) ${ }^{6}$ underlined the significant heterogeneity between centers and across countries regarding the current management of IRD patients in Europe. This applies not only to genetic testing and genetic counselling, but also to referral pathways, access to expert centers, ancillary diagnostic tests, among others. To improve the care of IRD patients in Portugal, we need to urgently address four pivotal unmet needs: 1) improve disease awareness and education; 2) provide equitable access to genetic testing and genetic counselling; 3) establish referral pathways; and 4) develop a national IRD registry.

\section{Disease awareness and education}

One of the most important issues is the dis- and/or misinformation that exists towards IRDs. It is crucial to raise awareness and educate decision/policy-makers, the general public, clinicians, and other healthcare workers about these visually incapacitating diseases. Only with this background work can patients be granted full clinical, familial, social, and economic support. Strategies to improve disease awareness include position papers written by experts in the field, targeted conferences/lectures/courses/preceptorships for healthcare professionals, media coverage and even social media actions. Ophthalmologists, pediatricians, and general practitioners (GPs) / family physicians are usually the first clinicians to encounter an IRD patient, thus

1. Ophthalmology Unit. Centro Hospitalar e Universitário de Coimbra. Coimbra. Portugal.

2. University Clinic of Ophthalmology. Faculty of Medicine. University of Coimbra. Coimbra. Portugal.

3. Clinical Academic Center of Coimbra. Coimbra. Portugal.

4. Ophthalmology Unit. Hospital de Braga. Braga. Portugal.

5. Ophthalmology Unit. Hospital da Senhora da Oliveira Guimarães. Guimarães. Portugal.

$\triangle$ Autor correspondente: João Pedro Marques. marquesjoaopedro@.gmail.com

Recebido: 26 de janeiro de 2021 - Aceite: 01 de fevereiro de 2021 - First published: 08 de abril de 2021 - Online issue published: 03 de maio de 2021 Copyright $\odot$ Ordem dos Médicos 2021 
making up the group where targeted educational actions are most needed. Recognizing clinical clues/red flags like nystagmus, low vision, constricted visual field, night blindness (nyctalopia) and photophobia is crucial for a timely referral to an IRD expert center. In preverbal children, abnormal visual behavior and nystagmus observed and reported by the parents should prompt an appropriate ophthalmological workup for IRD.?

\section{Genetic testing and genetic counselling}

Remarkable progress in understanding the genetics of IRDs resulted in the identification of roughly 300 diseasecausing genes (https://sph.uth.edu/retnet/). Several studies have confirmed that next-generation sequencing (NGS) panel-based genetic testing can be highly accurate, sensitive and reproducible in the molecular diagnosis of IRDs. ${ }^{8}$ However, this wealth of information is only slowly being translated into genetic diagnoses for individual patients, as significant barriers to testing still exist. In Portugal, the overall prevalence and genetic architecture of IRDs is largely unknown since access to genetic testing is not equitable. A critical goal for moving the field forward is to obtain a genetic diagnosis for every IRD patient, the importance of which cannot be overemphasized. In fact, having a genetic diagnosis is likely to be the single most important factor for gaining access to an approved treatment or clinical trial based on gene therapy. ${ }^{9}$ Furthermore, it allows accurate genetic counselling for the patient and other family members, along with prenatal testing. Additionally, it is a singularly important strategy for advancing the classification of mutations and corresponding phenotypes, and for evaluating the prognosis of specific disease-causing genes. In order to provide all IRD patients with the opportunity to undergo genetic testing, patient referral pathways must be in place so that patients may access expert centres easily. Portugal must draw up clinical recommendations or guidelines for genetic testing in IRDs, aiming to grant an equitable access to genetic testing and genetic counselling.

\section{Referral pathways}

Timely referral of patients with presumed IRDs to an ophthalmologist is critical. This applies especially to children since visual rehabilitation during the appropriate stages of visual development may prevent amblyopia. If the initial suspicion of IRD is confirmed by the ophthalmologist, the patient should be referred for genotyping. Now that treatment of RPE65 mutation-associated retinal degeneration is possible, establishing a genetic diagnosis is even more im- portant. Given the degenerative nature of IRDs, a window of opportunity for gene therapy exists and gene therapy candidates must be identified as soon as possible. A list of national IRD experts and IRD expert centers should be created and made available to ensure a smooth referral process. The European Reference Network for Rare Eye Diseases (ERN-EYE) is a unique and innovative cross-border cooperation platform between specialists for the diagnosis and treatment of rare or low prevalence complex eye diseases, where IRDs are included. The only Portuguese healthcare provider that integrates the ERN-EYE is Centro Hospitalar e Universitário de Coimbra (CHUC). However, appropriate dissemination of this information is warranted, especially to those that deal with IRD patients - ophthalmologists, pediatricians and GPs.

\section{National IRD registry}

A national, web-based registry for IRDs is able to empower patients and community organizations, while supporting formal partnerships with investigators and stakeholders in the global aim to develop high-value, high-utility research. ${ }^{10}$ In 2020, the IRD-PT registry (www.retina.com. pt) was launched with the mission to generate important knowledge and collect high-quality longitudinal data on the epidemiology, genomic landscape, genotype-phenotype correlations and natural history of IRDs in Portugal. ${ }^{10}$ Hopefully, this invaluable resource will both boost and excel clinical research in the field of IRDs in our country, while facilitating patient access to clinical trials or new therapies.

\section{CONCLUSION}

Although rare in the general population, IRDs occupy a key position in current efforts to develop innovative therapies for blinding diseases. Despite remarkable advances witnessed in the field, complex challenges subsist. This position paper from the Ophthalmic Genetics Group of the Portuguese Society of Ophthalmology identifies four pivotal unmet needs along with reasonable solutions to address them, aiming to improve management of IRDs and preparing the upcoming approval of voretigene neparvovec in Portugal.

\section{COMPETING INTERESTS}

The authors declare they have no conflicts of interest.

\section{FUNDING SOURCES}

No funding was available for the elaboration of this manuscript.

\section{REFERENCES}

1. Weisschuh N, Obermaier C, Battke F, Bernd A, Kuehlewein L, Nasser F, et al. Genetic architecture of inherited retinal degeneration in Germany: a large cohort study from a single diagnostic center over a 9-year period. Hum Mutat. 2020;41:1514-27.

2. Maguire AM, Bennett J, Aleman EM, Leroy BP, Aleman TS. Clinical perspective: treating RPE65-associated retinal dystrophy. Mol Ther. 2020 (in press). doi: 10.1016/j.ymthe.2020.11.029.

3. Russell S, Bennett J, Wellman J, Chung D, YU ZF, Tillman A, et al. Effi-

cacy and safety of voretigene neparvovec (AAV2-hRPE65v2) in patients with RPE65-mediated inherited retinal dystrophy: a randomised, controlled, open-label, phase 3 trial. Lancet. 2017;390:849-60.

4. Maguire A, Russell S, Wellman J, Chung D, Yu ZF, Tillman A, et al. Efficacy, safety, and durability of voretigene neparvovec-rzyl in RPE65 mutation-associated inherited retinal dystrophy: results of phase 1 and 3 trials. Ophthalmology. 2019;126:1273-85.

5. Shah M, Shanks M, Packham E, Williams J, Haysmoore J, Maclaren 
$\mathrm{T}$, et al. Next generation sequencing using phenotype-based panels for genetic testing in inherited retinal diseases. Ophthalmic Genet. 2020;41:331-7.

6. Lorenz B, Tavares J, van den Born L, Marques J, Scholl H. Current management of inherited retinal degenerations (IRD) patients in Europe. Results of a multinational survey by the European Vision Institute Clinical Research Network EVICR.net. Ophthalmic Res. 2021 (in press). doi: 10.1159/000514540.

7. Suppiej A, Marino S, Reffo ME, Maritan V, Vitaliti G, Mailo J, et al. Early onset retinal dystrophies: clinical clues to diagnosis for pediatricians. Ital J Pediatr. 2019;45:168.

8. Consugar MB, Navarro-Gomez D, Place EM, Bujakowska K, Sousa
M, Fonseca-Kelly Z, et al. Panel-based genetic diagnostic testing for inherited eye diseases is highly accurate and reproducible, and more sensitive for variant detection, than exome sequencing. Genet Med 2015;17:253-61.

9. Thompson D, Ali R, Banin E, Branham K, Flannery J, Gamm D, et al. Advancing therapeutic strategies for inherited retinal degeneration: recommendations from the Monaciano Symposium. Invest Ophthalmol Vis Sci. 2015;56:918-31.

10. Marques JP, Carvalho AL, Henriques J, Murta JN, Saraiva J, Silva R. Design, development and deployment of a web-based interoperable registry for inherited retinal dystrophies in Portugal: the IRD-PT. Orphanet J Rare Dis. 2020;15:304. 